\title{
THE IMPLEMENTATION OF SMART MEASUREMENT FROM THE VIEWPOINT OF THE CONSUMERS
}

\author{
Vivien Szunyog
}

\begin{abstract}
"Electricity suppliers, in accordance with the appropriation of the European Union, the Hungarian government, and the Hungarian Energy and Public Utility Regulatory Authority, have begun the preparations for implementing the so-called smart measurement system." - That is how those consumers who were planned to receive a smart meter in their household were notified.
\end{abstract}

The new meter was planned to have been set up within a month by the company's employed mechanics.

These are the reasons why I have chosen to examine the installment of smart meters from the viewpoint of the consumers. What benefits would this change bring to them? How can they save money by using smart meters? How can they influence their consumption? Are they willing to change their consumption habits? In my work, the starting point will be a sociodemographic attitude research that has already been carried out.

Besides all this, I am going to describe the disadvantages of smart meters as well. I am going to present what other inventions suppliers are planning after the installment of smart meters by performing some calculations with the smart web portal's smart tariff calculator. Finally, I am going to summarize the most important thoughts and conclusions.

Keywords: Smart metering, smart tariff, consumer advantages and disadvantages, smart web portal

JEL classification: $Z$ - Other special topics

\section{Nowadays, everything is "smart"}

Recently, we have been hearing the word "smart" more and more often in different situations and contexts. Let us for instance take the term "smartphone", which is an expression learnt by children just as easily as the word "car", and as a "smart TV" becomes one of the most basic objects of a household. Whether we like it or not, youth nowadays is surrounded by "smart" technology from birth.

The word "smart" in the energy industry is basically present everywhere. It began a few years ago, barely noticeably, with the term "smart meter". Concepts such as "smart home", "smart grid", and then "smart city" and "smart area", appeared only later.

(As an interesting fact, I would like to mention that Györ is now to the forefront of the world's smart cities.) 


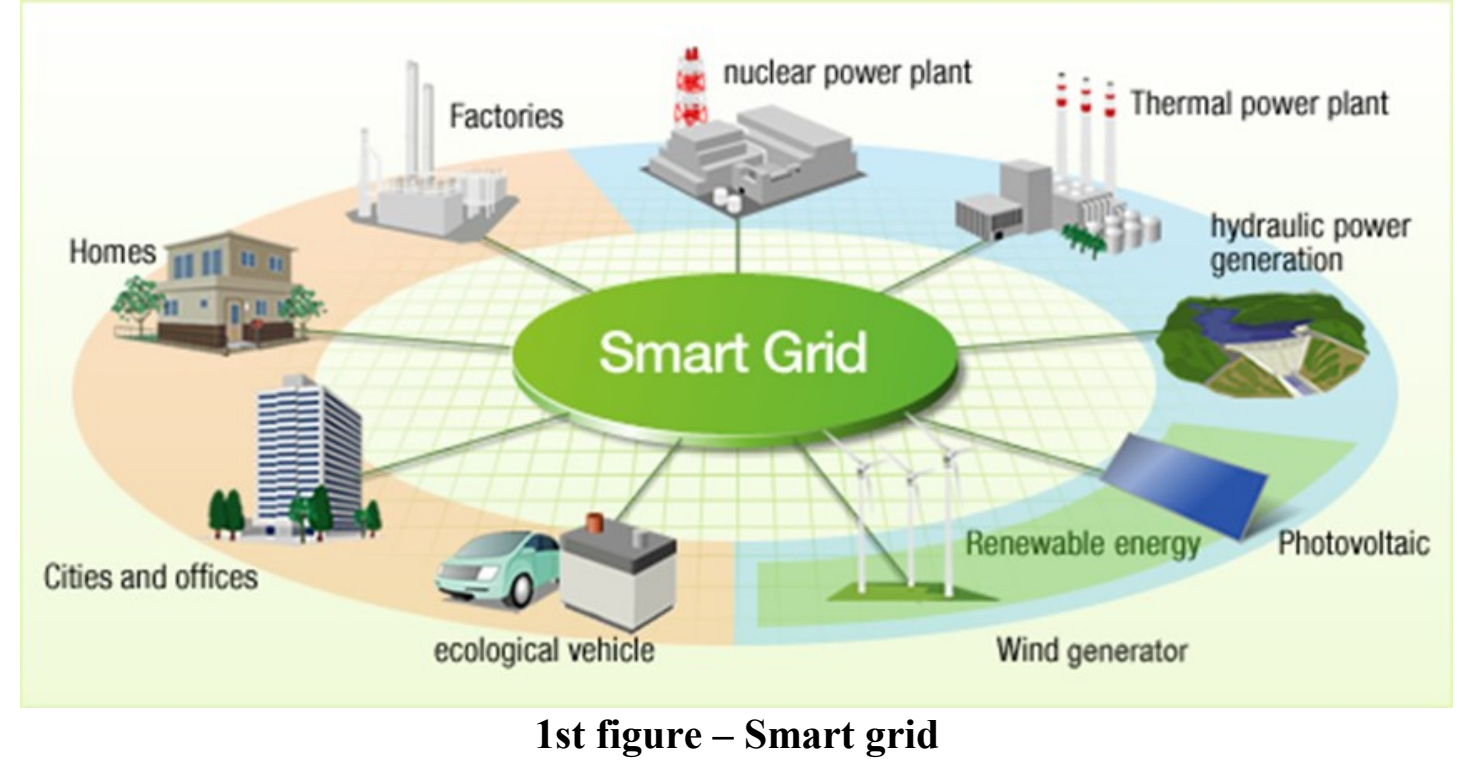

Within the energy industry, the area of distribution networks was one of the first to use the term "smart", in relation to smart machines and solutions. The definition in the dictionary perfectly matches the "smart" technologies and systems of the distribution networks.

The wide-range development that took place at the turn of the 21 st century, such as the miniaturization of electronic systems and computer technologies, laid down the basis for the application of artificial intelligence in areas where it was hardly conceivable before. The distribution of energy is one of these areas.

For more than a hundred years, there was only one simple mechanical solution which only meant that the energy was delivered directly from central sources to the end users. Distribution channels, electric wires and pipes were manually manageable, and the system was not too complicated. The consumption of end users was measured by simple mechanical or electromechanical tools, which were read by mechanics.

Computers, which were starting to gain popularity in the second part of the 20th century, contributed to the more efficient management and maintenance of distribution enterprises, as well as they allowed the gradual improvement of customer service. Later, computers facilitated the digitalization and partly the management of distribution network data, but that was all they could offer.

The 21st century brought about a giant boom in the use of new natural electrical resources, especially sun and wind power plants, which were connected to distribution networks in large numbers. It resulted in the need to review and reconsider the existing way of managing distribution networks as these new, rather unstable resources brought dynamic elements into the electrical system. At the point of switching such resources into the electrical system, the electric power was, for instance because of the weather, either too much or not enough. This can change even in a few minutes which means that distribution companies have to face the challenge of providing electric power to their clients in a reliable and high quality way. Given the fact that until now, no one has managed to invent an efficient, cheap, and feasible way to store superfluous energy, there is only one possible way left - the dynamic management of consumption. 
For the dynamic management of an electric network, the distributor needs a large amount of up-to-date data, with real-time processing. This does not only include the information of different measurement points of the network, but more importantly, it includes the information of the individual consumption points as well. The next step is based on the processing of the collected data, such as the direct or indirect management of different electric devices, in favor of creating the balance between the production and the consumption of electric energy. This, however, exceeds human capabilities. That is why it is necessary to create a network that is able to handle energy conditions by itself, with artificial intelligence based on "smart" components. As a matter of fact, we need to build a "smart" network in a "smart" area or "smart" city - in short, we need a "smart" utility network.

For all this discussed above, the first and smallest component is a "smart" consumption meter that my thesis is structured around.

\section{Introduction}

"Electricity suppliers, in accordance with the appropriation of the European Union, the Hungarian government, and the Hungarian Energy and Public Utility Regulatory Authority, have begun the preparations for implementing the so-called smart measurement system." - That is how those consumers who were planned to receive a smart meter in their household were notified. They also described that during the first phase, they would like to examine and evaluate the new functions and possibilities on locations chosen by mechanical and consumptionstatistical perspectives.

According to the letter, this operation would not mean financial or any other inconveniences for the consumers, for us, and the mechanical standard of the service would as well remain unchanged. The new meter was planned to have been set up within a month by the company's employed mechanics. That means we do not have much time to get informed. Elderly or less up-to-date persons were probably unable to decide whether this change would bring about better or worse conditions for them.

These are the reasons why I have chosen to examine the installment of smart meters from the viewpoint of the consumers. What benefits would this change bring to them? How can they save money by using smart meters? How can they influence their consumption? Are they willing to change their consumption habits? In my work, the starting point will be a research that has already been carried out. Sonda-Ipsos has conducted a sociodemographic attitude research in which I have participated as a representative of the electricity supplier (which I would not like to name here).

This supplier has the largest client base in Hungary regarding electricity.

\begin{tabular}{lc}
\hline \multicolumn{1}{c}{ Area } & Number of Clients \\
\hline Southern Transdanubia (power) & 760143 \\
\hline Northern Transdanubia (power) & 1000953 \\
"Tiszántúl" (power) & 765797 \\
\hline
\end{tabular}

1st chart - The number of Clients of the electricity supplier 
Besides all this, I am going to describe the disadvantages of smart meters as well. I am going to present what other inventions suppliers are planning after the installment of smart meters by performing some calculations with the smart web portal's smart tariff calculator. Finally, I am going to summarize the most important thoughts and conclusions.

\section{What makes a smart meter "smart"?}

Through wired or mobile connection, smart meters are connected to the measurement center so they regularly indicate and store the current consumption. They can be controlled from the measurement center (remotely), so they do not require personal reading, and they facilitate the billing of the exact amount of power consumed.

\section{The advantages of smart meters}

Smart meters make the consumers' life easier. Smart accounting replaces annual accounting, monthly dictation, and the invoice is raised based on the monthly consumed, remotely read data. Quarter measurement data can be found on the smart web portal (or on other displayers: home display, mobile applications, etc.). There is an opportunity to apply multi-zone smart tariffs, so therefore, smart meters enhance conscious consumer behavior. By quarter measurement data, there is a possibility to alert and send notifications, and several utilities can publish their consuming data on one interface.

Another great advantage is cost-efficiency. Families that are unable to pay for a longer period of time might be cut off from power supplies. In this case, consumers undertake the high cost of reconnection. However, in the case of smart meters, only a part of this cost needs to be paid since one can cut down on the personal involvement of the mechanic.

\section{The results of the sociodemographic research}

The research conducted by Ipsos-Ariosz examined consumers from across the country by providing certain selection criteria (distorting factors had to be excluded).

The process contained a test and a control panel as well. They installed smart meters in both panels, but only test panel owners were notified of the smart meter installment, and about its advantages. Consumers in the control panel did not get a notification about the use of smart meter, only about the meter change.

The company's staff were examining the consumers, their property in the consuming area, and the electrical equipment within the property. They were also examining how much time consumers were spending at home, and what sorts of consuming activities they were having that required electricity.

I would like to highlight the most important results of the research.

Concerning the change in consumer habits, participants (in the test panel)...

- $56 \%$ is open to change their consuming activities

- $42 \%$ would not like to change their consuming activities

The vast majority of consumers (86\%) would expect a monthly amount of 1000 HUF saving for implementing a change in their consumer habits. The largest proportion of household 
activities to be changed concerns the use of washing machines, dishwashers, bread makers, and irons. In addition, panel owners showed significant flexibility in cutting down the charging of accumulator-based equipment.

In terms of attitude towards smart meters, $58 \%$ of the test panel owners were optimistic, $9 \%$ were pessimistic. $11 \%$ of the respondents could not form an opinion. $24 \%$ of the test panel owners was still contemplating as they could name an equal number of positive and negative attributes.

\section{The results of the consumer attitude research}

Consumers were categorized based on the following criteria:

- Innovativeness

- Conscious lifestyle

- Frugality

- Impulsivity

- Energy saving

- Environmental consciousness

The categories that were formed based on the above criteria are the following.

Modern, willing to act:

People of this group are rather innovative, environmentally conscious. They are usually frugal and aware of their power consumption.

They are usually medium- and big consumers. A bigger proportion of this group lives in Budapest and in other County Authorities. They are usually middle-aged. The number of educated and wealthy people in this group is above the average.

\section{Modern, observer:}

People of this group are innovative, their way of thinking is environmentally conscious. However, they take little action to protect the environment, they are typically wasteful of their income and their energy as well.

They are rather big consumers. A bigger proportion of this group lives in Budapest and in other County Authorities. The number of young and middle-aged people is above the average, so is the number of educated and wealthy group members.

\section{Traditional economizer:}

People in this group are mostly not innovative. Environmental consciousness is not really important to them. However, the proportion of economizers is the highest in this group, regarding both saving their income and their energy, though the reason behind it is not environmental consciousness.

Typically, they are small- and medium consumers. The number of women and village people is really significant. The proportion of less educated and less wealthy members is higher. Economizers have the fewest active members. 


\section{Consumption-oriented:}

People of this group have an ordinary skill for innovativeness. Concerning environmental consciousness, group members have a strongly negative attitude. Frugality (both with their income and with energy) is the least typical in this group but the positive attitude towards shopping is very high.

There is no typical category for consumption level. The number of people living in towns is slightly above the average. They are average citizens regarding their age, education, and financial background.

\section{The disadvantages of smart meters}

To be honest, we cannot really speak about disadvantages in connection with smart meters. The advantages listed above can become disadvantages from the viewpoint of "bad consumers". I would call them "bad" because they do not pay the actual amount consumed, namely smart meters can help discover electricity theft. If the suspicion is proved, the consumer can be immediately disconnected from the center, there is no need for dispatching (the personal involvement of the mechanic).

What is solicitous for me is that the price of reconnection decreases. Earlier on, some households were held back by the high price of reconnection, so they rather paid the bills on a regular basis, but from now on, they might end up hesitating more easily.

\section{Smart tariff at the supplier}

It is a tariff on the competitive market which provides the followings:

- If the client rearranges a part of their consumption from the highest consumption period to the lowest one, the total will be lower.

- The aim is not to make smart tariff cheaper. It should only be cheaper if the rearrangement is made.

The lowest consumption period shall be the period between $8 \mathrm{pm}$ and $6 \mathrm{am}$, the highest shall be between 6 am and $8 \mathrm{pm}$.

In my opinion, electricity suppliers could divide the highest period into three more periods regarding consumption. There could be an extra tariff added to the period between 6 am and 9 am, and to the one between $5 \mathrm{pm}$ and $8 \mathrm{pm}$, so between 9 am and $5 \mathrm{pm}$, there would be a discounted rush hour tariff. That is how consumers would indeed rearrange their consumption.

\section{Web portal}

Web portal helps consumers find their way around in smart measurement.

Here the consumer can see the measurement data by using an individual identification number. They need to register with an e-mail address, connecting either a production number for the consumer's meter, a business partner ID, or an ID for the point of delivery to it. Of course, the consumer has to declare officially whether the e-mail address belongs to them. In case of a meter change, the installment and the uninstallment date define the continuity of the data. 
Consumption data can be displayed in two ways:

- In a graphic form (line- or bar chart) - several measurement data can be shown at once

- In a tabular format - these can be imported to Excel

The consumer has to set the start date, and then set the measurement data (time period, which now can be 1 month maximum). Data density can be set as well:

- In a 15-minute breakdown

- In an hourly breakdown

- In a daily breakdown

- In a weekly breakdown

Users have the possibility to compare a specific database with an earlier one, for instance with the values of the past month of year.

One can display how much the consumption of the given period was, with different tariffs. This helps the consumer to calculate which price plan would be the most suitable for their consumption habits.

\section{Results and discussion}

Smart accounting replaces annual accounting, monthly dictation, and the invoice is raised based on the monthly consumed, remotely read data. Quarter measurement data can be found on the smart web portal (or on other displayers: home display, mobile applications, etc.). There is an opportunity to apply multi-zone smart tariffs, so therefore, smart meters enhance conscious consumer behavior. By quarter measurement data, there is a possibility to alert and send notifications, and several utilities can publish their consuming data on one interface.

Installing smart meters is beneficial for the consumers as well because they can save effort, and they make the consumers' life easier.

\section{Conclusion}

Based on the attitude research, regarding tariff we can say that the current construction is not tempting for the consumers because of the Hungarian utility cost reduction. After launching the project at the energy supplier, maintaining the smart tariff would not be feasible. If there was no utility cost reduction, more people would choose the smart tariff.

It is possible that there is a need for elaborating a new tariff, which is tempting for the consumer and for the supplier as well. The receptive target can already be spotted based on the research. (However, it is not worth for the company to implement a tariff that is cheaper than the previously given one, so they need to wait until the utility cost reduction will be abolished).

In connection with the website, experience shows that both smart websites and smart tariffs received very little interest from the population.

In order to evoke more interest, either in the advantages of smart measurement, in the webbased consumption monitoring site, or in the smart tariff, the project would require more intensive and colorful ("marketable") communication; with that, it would also require more investment. 
All in all, the installment of smart meters would make consumers' life easier, of course, only for those who pay their bills on a regular basis as the company would like to eliminate illegal service usage.

I am one of those consumers who would like to monitor their consumption on the web portal, and the smart tariff would be favorable for me. I would gladly experiment with changing my consumption habits, and I would be curious to see how I could maximize cost-efficiency. For me, splitting the smart tariff would result in saving more costs. I usually use the washing machine and the dishwasher between $21 \mathrm{pm}$ and 12 am because of my routine. Unfortunately, sometimes we forget to dictate the meter reading at the end of the month with my flat mates because it is hard to follow who's the next in line.

If I were to advise anyone, I would kindly recommend the installment of a smart meter. Besides the advantages mentioned above, the disadvantages do not concern regularly paying customers.

I am truly waiting for the installment of these smart meters not just to measure electricity- and gas consumption, but also to measure water and district heating.

\section{References}

1. Szonda Ipsos, Ariosz - Sociodemocratic- and attitude research (2014)

2. http://www.britishgas.co.uk/smarter-living/control-energy/smart-meters/benefits-ofsmart-meters.html (2015.05.24. 12:50)

3. www.pge.com/en/myhome/customerservice/smartmeter/benefits/index.page (2015.05.24. 12:57)

4. http://en.wikipedia.org/wiki/Smart_meter (2015.05.24. 13:20)

5. http://www.hitachi.com/environment/showcase/solution/energy/smartgrid.html (2015.05.24. 13:30)

6. http://www.eon.hu/A_vilag_okos_varosainak_elvonalaba_kerult_Gyor (2015.05.24. $13: 45)$ 